\title{
Correlation between Forearm Bone Mineral Density and Body Composition in Japanese Females Aged 18-40 years
}

\author{
Misao ARIMATSU1 ${ }^{1}$, Takao KITANO², Naoko KITANO³, Takeaki INOMOTO², \\ Masahiro SHONO² and Makoto FUTATSUKA ${ }^{2}$ \\ ${ }^{I}$ Department of Fundamental Nursing, School of Health Sciences, Kumamoto University, Kumamoto, Japan \\ ${ }^{2}$ Department of Public Health, Graduate School of Medical Sciences, Kumamoto University, Kumamoto, Japan \\ ${ }^{3}$ Division of Food and Health Environment, Prefectural University of Kumamoto, Kumamoto, Japan
}

\begin{abstract}
Objective: The purpose of this study was to clarify the relationship between forearm bone mineral density (BMD), body mass index (BMI), and body composition focusing on body fat percentage (BF\%) in Japanese females 18 to 40 years old.

Methods: Subjects were 2,280 females 18-40 years old. Anthropometric measurements were taken, and a medical history was obtained by questionnaire, including age at the time of the study and age at menarche. BF\% was measured by bioelectrical impedance analysis. Forearm BMD was measured using dual-energy X-ray absorptiometry (DXA). The correlations of BMD with BMI and $B F \%$ were analyzed using a structural equation model.

Results: The standardized regression coefficients for the path from BMI to BMD and the path from $B F \%$ to $B M D$ were 0.538 and -0.184 respectively. The squared multiple correlation of BMD was 0.146. In addition, the standardized regression coefficient for the path from BMI to BF\% was 0.896 .

Conclusion: The results showed a positive correlation between BMD and BMI and an inverse correlation between $\mathrm{BMD}$ and $\mathrm{BF} \%$. At the same time, it was noted that $\mathrm{BF} \%$ increased with $\mathrm{BMI}$. This indicated that BMD is dependant on BF\% in subjects who have a similar BMI. Therefore, this study concluded that it is necessary to take body composition measurements into account when examining the relationship between BMI and BMD, especially in young females.
\end{abstract}

Key words: bone mineral density (BMD), dual-energy X-ray absorptiometry (DXA), body composition, young Japanese female, cross-sectional study

\section{Introduction}

Bone mass in humans generally reaches its peak during the twenties and thirties and decreases along with bone mineral density (BMD) as one ages $(1,2)$. It is also known that raising peak bone mass levels is useful in preventing osteoporosis. Therefore, although osteoporosis is usually considered a condition of the elderly, it is important to be aware that preventative steps can be taken while young.

When looking at the correlations between BMD and physique, there is often a strong relation between BMD and

Received Dec. 25, 2003/Accepted Apr. 4, 2005

Reprint requests to: Misao ARIMATSU

Department of Fundamental Nursing, School of Health Sciences, Kumamoto University, 4-24-1 Kuhonji, Kumamoto 862-0976, Japan

TEL: +81(096)373-5512, FAX: +81(096)373-5512

E-mail: arimatsu@hs.kumamoto-u.ac.jp body weight, with leanness being recognized as one of the risk factors associated with osteoporosis (1-3). This means that within a given age group people with relatively low body weights are likely to have lower BMD. Recent National Nutrition Surveys in Japan report that a large number of women in their twenties and thirties have very slim builds as measured by BMI (4-6).

According to the results of the 2001 National Nutrition Survey (7), women having a slim build (BMI of $18.5 \mathrm{~kg} / \mathrm{m}^{2}$ or less) accounted for $20.0 \%$ of the 20 through 29 age group, and $16.0 \%$ in the 30 through 39 age group. From the viewpoint of the bone life cycle, extreme leanness during a woman's twenties and thirties is not advisable. On the other hand, Fujise et al. (8) reported that $66.2 \%$ of obese female college students $(\mathrm{BF} \%$ greater than $30 \%$ ) were not classified as obese according to their BMI scores (BMI was more than $20 \mathrm{~kg} / \mathrm{m}^{2}$ but below $24 \mathrm{~kg} / \mathrm{m}^{2}$ ). Yamagishi et al. (9) reported that female college students with a BF\% over $30 \%$ often did not have a BMI over 
$23 \mathrm{~kg} / \mathrm{m}^{2}$. That study showed that BMI was a poor index of obesity, especially in individuals with a BMI below $25 \mathrm{~kg} / \mathrm{m}^{2}$. Moreover, Ohno et al. (10) reported that obesity findings as measured by BMI were not consistent with those according to $\mathrm{BF} \%$ in the $40 \%$ to $50 \%$ of middle-aged or older women whose BMI was $20 \mathrm{~kg} / \mathrm{m}^{2}$ or less. These studies showed that BMI and $\mathrm{BF} \%$ do not correlate exactly in contemporary women. They also demonstrated that the characteristics of obesity can not be adequately explained by BMI alone, and indicated that body composition must be taken into account in order to fully understand obesity characteristics.

A number of studies on osteoporosis have focused on menopausal women, and there are many reports on the associations of BMD with body weight and BMI (11-13). Other studies have investigated the influence of fat-free mass and fat-mass on bone density from the perspective of body composition, but no distinct influential factors have been identified (12-14). This is probably because in addition to a change of physique, there is also a change in the female hormonal state after menopause. In other words, a combination of factors influenced bone condition, including menopausal hormonal changes, hormonal secretion, eating habits, and/or lifestyle (15, 16).

It is therefore necessary to take such lifecycle factors into account when attempting to evaluate the overall bone condition of women. Moreover, in women, the grade of obesity on appearance may differ from the actual measured state. Therefore, when discussing the relation between physique and bone condition in women, it is necessary to consider body composition. It is especially important to clarify the correlation between body composition and bone condition for women in their twenties and thirties when bone mass reaches its peak $(1,2)$. This study discusses the correlation of BMD with physique, focusing on body composition, in a subject group of women aged 18 through 40 years.

\section{Methods}

\section{Subjects}

This study was conducted from April 1994 to March 1999 in Kumamoto City, Japan. During this period a total of 3,460 BMD measurements were taken in women aged 18 to 40 years (mean age 33.0 44.2 years) during annual Women's Medical Examinations promoted by the city. The subjects were volunteers living in Kumamoto City, Japan, and were recruited through advertisements in the city's PR news bulletin.

The volunteers included 491 women who had received BMD measurements two or more times. In these cases, only the first measurements were used in this study. As a result, 2,793 women were registered in the database. Pregnant women, women having a history of chronic disease, those taking medications known to affect bone metabolism (i.e. gynecologic disease, liver disease, renal disease, thyroid treatment, or diabetes mellitus) and those using any drugs known to affect bone or calcium metabolism were excluded. In the end 2,280 women met the inclusion criteria. This study was conducted in conformity with the Helsinki Declaration; subjects were informed of the protocol and methods before being registered for the study.

\section{Measurements}

BMD of the forearm (distal) of the non-dominant hand was measured by dual-energy X-ray absorptiometer using a DTX-200 (OSTEOMETER, TOYO MEDIC, Tokyo, Japan). Measurements were taken at health centers in Kumamoto City by radiologists trained in the proper use of the instrument. In addition, the instrument in use was checked regularly to ensure its accuracy.

Body height was measured by YG-200 (YAGAMI, Nagoya, Japan) in a barefoot standing position. Body weight and BF\% were measured simultaneously with the subjects in a barefoot standing position using a TBF-102 (TANITA Corp. Tokyo, Japan). Clothing was calculated as $1 \mathrm{~kg}$ tare in body weight measurements. Estimates of $\mathrm{BF} \%$ were calculated from an equation based on body density measured by underwater weighing. This BF\% model has been described in detail elsewhere (17).

A questionnaire was given to the subjects requesting information regarding personal health and medical history: bone fractures, age at menarche, menstrual history, childbirth and lactation experience, diet and exercise, estimated weekly intake of certain foods, consumption of luxury items, and work history. Afterwards, a public health nurse validated the information for the study. We conducted our analysis without considering the influence of lifestyle on BMD, based on the view that physique itself reflected lifestyle factors to a certain extent.

\section{Statistical analysis}

Anthropometric characteristics of the subjects are shown, along with data regarding mean age at menarche, mean body measurements, and standard deviations according to age group. Subjects were divided into four groups by BMI $\left(\mathrm{kg} / \mathrm{m}^{2}\right)$, according to the BMI classes established for adult Asians (18): Underweight $\left(\mathrm{BMI}<18.5 \mathrm{~kg} / \mathrm{m}^{2}\right)$, Normal $(18.5 \leq \mathrm{BMI}<$ $\left.23 \mathrm{~kg} / \mathrm{m}^{2}\right)$, At-risk $\left(23 \leq \mathrm{BMI}<25 \mathrm{~kg} / \mathrm{m}^{2}\right)$, and Obese (BMI $\geq$ $25 \mathrm{~kg} / \mathrm{m}^{2}$ ). Comparisons among the groups were made by ANOVA. Pearson correlation coefficients were calculated in order to discuss correlations among all the variables (age, height, weight, $\mathrm{BMI}, \mathrm{BF} \%$, and $\mathrm{BMD}$ ), and partial correlation

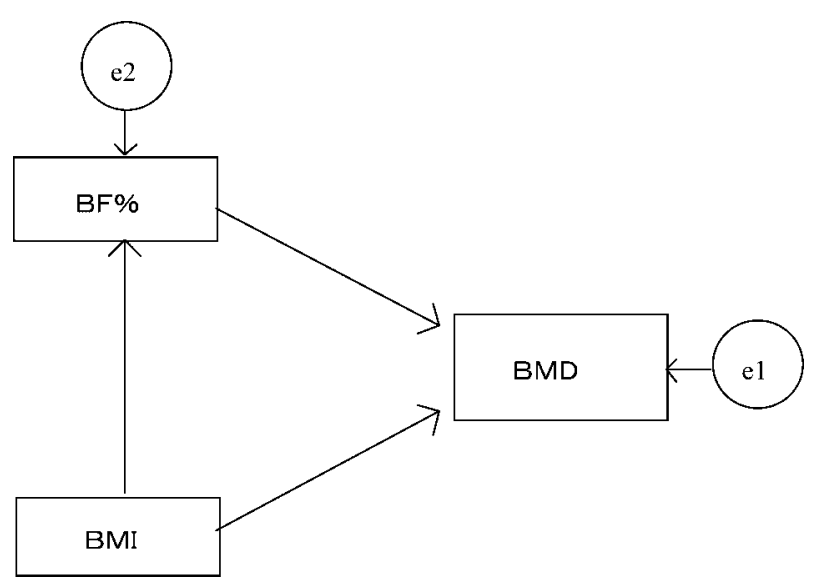

Fig. 1 The relationship between BMI, BF\% (Body fat percentage) and BMD by structural equation model. e1, e2: error. 


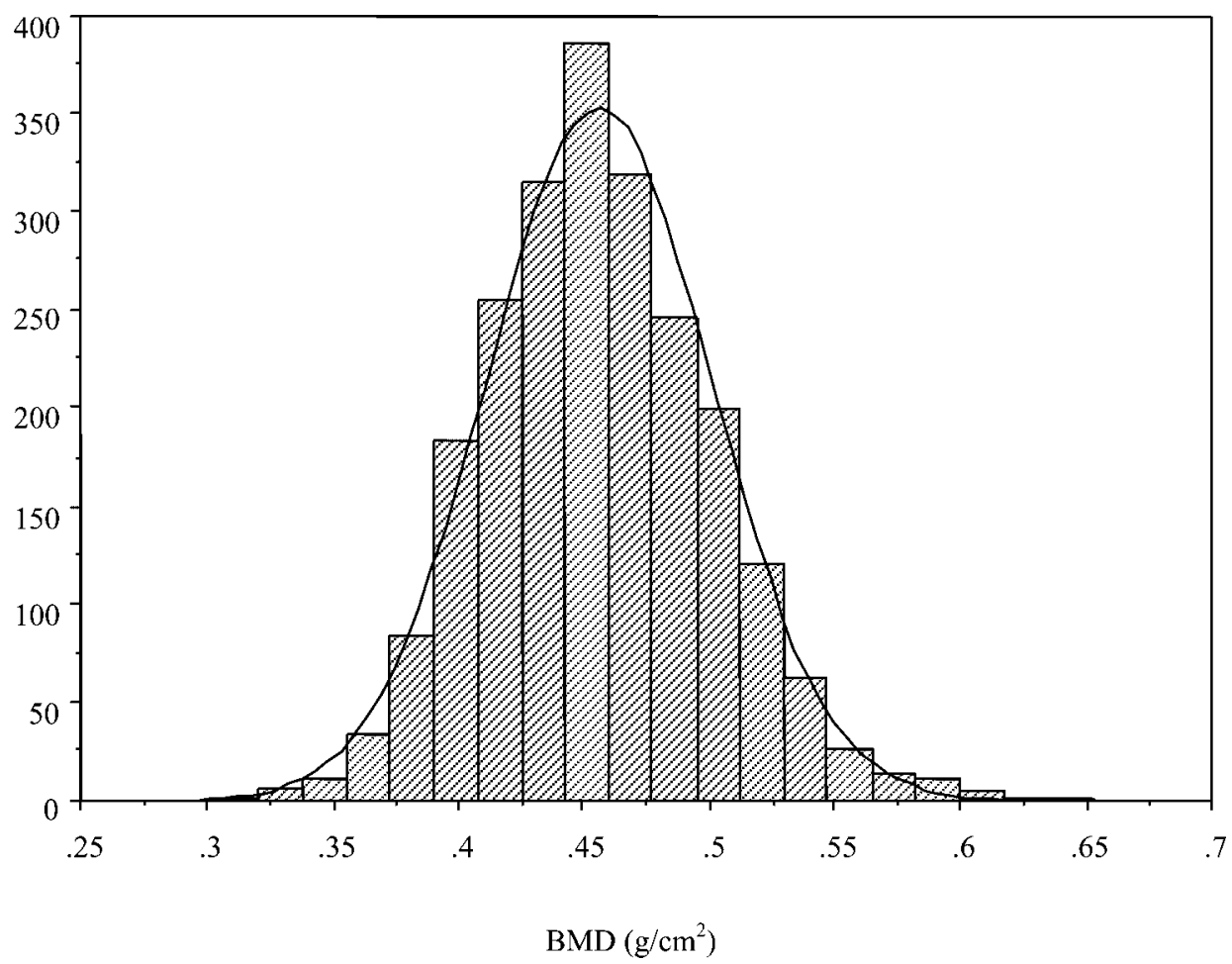

Fig. 2 Distribution of forearm bone mineral density.

coefficients were calculated to analyze correlations of BMD with $\mathrm{BMI}$ and $\mathrm{BF} \%$, respectively. The regression model to obtain $\mathrm{BF} \%$ described by Sakamoto et al. (17) uses height and weight, therefore, multicollinearity will appear between BMI and $\mathrm{BF} \%$ if the multiple regression model is applied. To avoid multicollinearity a hypothesized structural equation model (SEM) was formulated (Fig. 1), and standardized regression weights for BMI and BF\% were calculated against BMD.

Statistical analyses were performed using the Stat View 5.0J software package (SAS Institute, Japan). The SEM analyses were calculated with AMOS Ver. 5 (SPSS, Japan). Results were considered significant when the p-value was less than 0.05 .

\section{Results}

Physiological characteristics

The distribution of forearm BMD measurements is shown in Figure 2. The mean forearm BMD value was $0.456 \pm 0.045$

Table 1 Characteristics of the subjects

\begin{tabular}{|c|c|c|c|}
\hline & $\begin{array}{c}\text { Total } \\
\mathrm{N}=2280\end{array}$ & $\begin{array}{c}18-29 \text { years } \\
n=472\end{array}$ & $\begin{array}{c}30-40 \text { years } \\
n=1808\end{array}$ \\
\hline & Mean \pm SD & Mean \pm SD & Mean \pm SD \\
\hline Age at menarche (year) & $12.6 \pm 1.2$ & $12.6 \pm 1.3$ & $12.6 \pm 1.2$ \\
\hline Height $(\mathrm{cm})$ & $157.8 \pm 5.0$ & $158.3 \pm 5.0$ & $157.7 \pm 5.0 *$ \\
\hline Weight (kg) & $51.0 \pm 6.9$ & $50.0 \pm 6.5$ & $51.2 \pm 6.9 * *$ \\
\hline BMI $\left(\mathrm{kg} / \mathrm{m}^{2}\right)$ & $20.5 \pm 2.6$ & $20.0 \pm 2.5$ & $20.6 \pm 2.6^{* *}$ \\
\hline body fat percentage $(\%)$ & $24.6 \pm 5.4$ & $24.0 \pm 5.4$ & $24.8 \pm 5.4^{* *}$ \\
\hline
\end{tabular}

Comparison between $18-29$ years and $30-40$ years by Student's t-test.

$*: \mathrm{p}<0.05, * *: \mathrm{p}<0.01$. $\mathrm{g} / \mathrm{cm}^{2}$, and the range was from $0.303 \mathrm{~g} / \mathrm{cm}^{2}$ to $0.652 \mathrm{~g} / \mathrm{cm}^{2}$.

Table 1 shows the anthropometric characteristics of the subjects along with the mean age at menarche, and the mean body measurements and standard deviations for each age group [twenties (18 29 years) and thirties (30 40 years)]. The mean weight, $\mathrm{BMI}$, and $\mathrm{BF} \%$ were significantly higher in the thirties group $(p<0.01)$, while height was significantly higher in the twenties group $(p<0.05)$. The mean age at menarche did not differ between the two groups.

On the questionnaire, the number of women answering "mostly regular" regarding the menstrual cycle during the previous six months was $1,806(79.2 \%)$. Those answering "irregular", "no menstruation (including lactation)", or "no answer" were $284(12.5 \%), 175$ (7.7\%) and 15 (0.6\%), respectively.

\section{Body composition and BMD}

Subjects were divided into four groups according to BMI characteristics: the underweight group $(452 ; 19.8 \%)$, the normal group $(1,506 ; 66.1 \%)$, the at-risk group $(198 ; 8.7 \%)$, and the obese group (124; 5.4\%).

Table 2 shows the anthropometric characteristics of each of the four groups. Members of the underweight group were significantly taller compared with the other three groups ( $p<0.05$, by ANOVA, Scheffe test). Body weight and BF\% increased significantly as BMI increased, in this order: Underweight group, Normal group, At-risk group, and Obese group. Similarly, the mean BMD increased significantly as BMI increased ( $p<0.05$, by ANOVA, Scheffe test). The BMD of each group was; Underweight: $0.436 \pm 0.042 \mathrm{~g} / \mathrm{cm}^{2}$; Normal: $0.456 \pm$ $0.042 \mathrm{~g} / \mathrm{cm}^{2}$; At-risk: $0.475 \pm 0.043 \mathrm{~g} / \mathrm{cm}^{2}$; and Obese: $0.502 \pm$ $0.048 \mathrm{~g} / \mathrm{cm}^{2}$. 
Table 2 Height, weight, BMI and body fat percentage compared by body mass index groups ${ }^{1}$

\begin{tabular}{|c|c|c|c|c|}
\hline & $\begin{array}{l}\text { Underweight } \\
\qquad \mathrm{n}=452\end{array}$ & $\begin{array}{l}\text { Normal } \\
n=1506\end{array}$ & $\begin{array}{l}\text { At risk } \\
\mathrm{n}=198\end{array}$ & $\begin{array}{l}\text { Obese } \\
n=124\end{array}$ \\
\hline & Mean \pm SD & Mean \pm SD & Mean \pm SD & Mean \pm SD \\
\hline Age (year)* & $32.0 \pm 4.5$ & $33.2 \pm 4.1^{\mathrm{a}}$ & $34.0 \pm 4.3^{\mathrm{a}}$ & $34.2 \pm 3.6^{\mathrm{a}}$ \\
\hline Height $(\mathrm{cm})^{*}$ & $158.7 \pm 5.2$ & $157.7 \pm 5.0^{\mathrm{a}}$ & $157.0 \pm 4.8^{\mathrm{a}}$ & $156.5 \pm 5.1^{\mathrm{a}}$ \\
\hline Weight $(\mathrm{kg})^{*}$ & $44.1 \pm 3.5$ & $50.7 \pm 4.3^{\mathrm{a}}$ & $58.8 \pm 4.0^{\mathrm{a}, \mathrm{b}}$ & $66.6 \pm 7.6^{\mathrm{a}, \mathrm{b}, \mathrm{c}}$ \\
\hline BMI $\left(\mathrm{kg} / \mathrm{m}^{2}\right)^{*}$ & $17.5 \pm 0.8$ & $20.4 \pm 1.2^{\mathrm{a}}$ & $23.8 \pm 0.6^{\mathrm{a}, \mathrm{b}}$ & $27.3 \pm 2.3^{\mathrm{a}, \mathrm{b}, \mathrm{c}}$ \\
\hline body fat percentage $(\%)^{*}$ & $18.6 \pm 2.4$ & $24.6 \pm 3.3^{\mathrm{a}}$ & $31.3 \pm 3.6^{\mathrm{a}, \mathrm{b}}$ & $36.4 \pm 5.6^{\mathrm{a}, \mathrm{b}, \mathrm{c}}$ \\
\hline $\operatorname{BMD}\left(\mathrm{g} / \mathrm{cm}^{2}\right)^{*}$ & $0.436 \pm 0.042$ & $0.456 \pm 0.042^{\mathrm{a}}$ & $0.475 \pm 0.043^{\mathrm{a}, \mathrm{b}}$ & $0.502 \pm 0.048^{\mathrm{a}, \mathrm{b}, \mathrm{c}}$ \\
\hline
\end{tabular}

I: Underweight: $\mathrm{BMI}<18.5$, Normal: $18.5 \leq \mathrm{BMI}<23$, At risk: $23 \leq \mathrm{BMI}<25$, obese: $25 \leq \mathrm{BMI}$.

Comparison between body mass index groups by ANOVA and post-hoc test by Scheffe.

$*: \mathrm{p}<0.05$.

a. $\mathrm{p}<0.05$ vs Under weight, ${ }^{\mathrm{b}}: \mathrm{p}<0.05$ vs Normal, ${ }^{\mathrm{c}}: \mathrm{p}<0.05$ vs At risk.

Table 3 Simple correlation coefficient between BMD and height, weight, BMI and body fat percentage

\begin{tabular}{|c|c|c|c|c|c|}
\hline & Height & Weight & BMI & body fat percentage & $\mathrm{BMD}$ \\
\hline Age & $-0.072 * *$ & $0.083 * *$ & $0.127 * *$ & $0.066^{* *}$ & $0.061 * *$ \\
\hline Height & & $0.372 * *$ & $-0.108 * *$ & $-0.108 * *$ & -0.038 \\
\hline Weight & & & $0.876^{* *}$ & $0.791 * *$ & $0.330 * *$ \\
\hline BMI & & & & $0.899 * *$ & $0.374 * *$ \\
\hline body fat percentage & & & & & $0.300^{* *}$ \\
\hline
\end{tabular}

$* *: \mathrm{p}<0.01$

Table 4 Standardized regression weights among BMD, BMI and body fat percentage by structural equation model

\begin{tabular}{lrr}
\hline & & \\
\hline BMD & $\leftarrow$ BMI & $0.538^{*}$ \\
BMD & $\leftarrow$ body fat percentage & $-0.184^{*}$ \\
body fat percentage $\quad \leftarrow$ BMI & $0.896^{*}$ \\
Squared Multiple Correlations $=0.146$ & \\
\hline$*: \mathrm{p}<0.05$. &
\end{tabular}

Table 3 shows simple correlations between BMD and anthropometric measurements. The correlation coefficients of BMD with body weight, $\mathrm{BMI}$ and $\mathrm{BF} \%$ were $\mathrm{r}=0.330, \mathrm{r}=0.374$, and $r=0.300$, respectively. The correlation coefficients of BMD with age and body height were $r=0.061$ and $r=-0.038$, respectively. No distinct correlations were found between BMD and anthropometric measurements in either simple regression or polynomial regression. BMI also had a strong correlation with $\mathrm{BF} \%(\mathrm{r}=0.899)$. Partial correlations of BMD with BMI and $\mathrm{BF} \%$ were calculated to adjust for their influence on BMD. BMI showed a weak correlation with BMD ( $\mathrm{r}=0.251)$, while no correlation was found between $\mathrm{BF} \%$ and $\mathrm{BMD}(\mathrm{r}=-0.088)$.

Evaluations of the influence of BMI and BF\% on BMD are shown in Table 4, based on the structural equation model shown in Figure 1 (the squared multiple correlation of $\mathrm{BMD}=0.146$ ). The standardized regression weights for the path from BMI to BMD and the path from BF\% to BMD were 0.538 and -0.184 , respectively. In addition, the standardized regression coefficient for the path from BMI to $\mathrm{BF} \%$ was 0.896. These figures indicate that $\mathrm{BF} \%$ and $\mathrm{BMD}$ increase as $\mathrm{BMI}$ increases, and also that increases in $\mathrm{BF} \%$ are associated with a decline in BMD.

In other words, in subjects with a similar BMI, the BMD is likely to decline as the $\mathrm{BF} \%$ rises.

\section{Discussion}

The subjects of this study were a Japanese female population in Kumamoto City who received health checks in a program announced in the City PR Bulletin. Of the subjects, $87.8 \%$ were either full-time housewives or part-time workers. The subjects showed no significant difference in body height and body weight compared with similar age groups in the National Nutrition Survey of Japan (4-6).

Optimal BMD measurements are obtained by measuring the whole body or the lumbar vertebrae. However, in this study measurements were taken in the forearm region because the subjects were females aged 18 through 40 years, and X-ray irradiation of the abdomen was considered an unacceptable risk. Previous studies reported that the correlation coefficient between forearm BMD and whole-body BMD or lumbar BMD ranged from $\mathrm{r}=0.60$ to $\mathrm{r}=0.75(19,20)$.

In recent years the leanness of young women has drawn attention as a health issue. "Healthy Japan 21", a policy paper issued by the Ministry of Health, Labor and Welfare, recommends the goal of securing a reasonable body weight for women during their twenties and thirties (21). Obesity is defined as a state in which excess adipose tissue accumulates, yet there have been reports of a trend toward masked-obesity, in which the $\mathrm{BF} \%$ is normal or high even when BMI is low. Among the subjects of this study, the BMI of those in their twenties and thirties was $20.0 \pm 2.5 \mathrm{~kg} / \mathrm{m}^{2}$ and $20.6 \pm 2.6 \mathrm{~kg} / \mathrm{m}^{2}$, respectively, and the $\mathrm{BF} \%$ was $24.0 \pm 5.4 \%$ and $24.8 \pm 5.4 \%$, respectively. The results of grouping by BMI showed that the mean $\mathrm{BF} \%$ of the at-risk group $\left(23 \leq \mathrm{BMI}<25 \mathrm{~kg} / \mathrm{m}^{2}\right)$ was $31.3 \pm 3.6 \%$, which is above the standard value for obesity of $30 \%$. The values found 
in this study were similar to those in other reports showing mean values categorized as masked-obesity.

Generally, positive correlations of BMD are reported with both body weight and BMI $(16,22)$. The results of this study, in which BMD was measured in the forearm, a region free from body weight load, also confirmed a simple positive correlation between BMD and body weight and between BMD and BMI. A similar trend has been observed in other studies reporting the association factors of radii (23-25). Lee et al. (26) also reported in their study on the relationship between BMD and body-fat mass or fat-free mass that positive correlations were recognized in the lower extremities and trunk, but that a similar correlation was seen only with fat-free mass in the upper extremities. This result suggested that regions which take body weight as a load, such as the lower extremities or trunk, are directly influenced by the weight of tissues, however, for upper body regions receiving less or little weight load, fat-free mass becomes more important as an influential factor.

Analysis of the structural equation model of BMD, with $\mathrm{BMI}$ and $\mathrm{BF} \%$ as the explanatory variables, produced a coefficient of determination of $0.146(14.6 \%)$. The results showed a positive correlation between $\mathrm{BMI}$ and $\mathrm{BMD}$, and an inverse correlation between $\mathrm{BF} \%$ and $\mathrm{BMD}$. The coefficient of determination is an index of how well the explanatory variables in the structural model describe the dependent variables. One might then question whether the model, with its coefficient of determination of $14.6 \%$, can be considered satisfactory. Previous studies have reported that BMD is influenced by diverse factors including experiences such as childbirth, and lifestyle factors including eating habits and exercise $(1,2,15,16,22,23$, $25)$. In addition, there is also a genetic contribution to BMD (1, $2,22)$. In this study, we assumed that lifestyle factors would serve as contributing factors to physique. Therefore, although the coefficient of determination of $14.6 \%$ was not particularly high, we were satisfied by the fact that the model was able to explain $14.6 \%$ of BMD in terms of $\mathrm{BMI}$ and $\mathrm{BF} \%$ alone.

However, lifestyle-related factors cannot be explained solely by physique. We plan to conduct a separate analysis of the relation between actual lifestyle and BMD based on the questionnaire results among these subjects.

According to the National Nutrition Survey, an increase in BMI was recognized among women during their forties. Sasaki et al. (27) reported that the mean BMI of women increased at age 30 years and above. Kim et al. (28) reported that the BF\% increased significantly from the age of 20 through 60 years. "Healthy Japan 21" also set itself the goal of solving the obesity problem while encouraging women to maintain an appropriate body weight during their forties. Based on these reports and findings, the $\mathrm{BMI}$ and $\mathrm{BF} \%$ of the subjects of this study are likely to increase in as they age. The present study found that $\mathrm{BMI}$ increases contributed to increases in $\mathrm{BF} \%$ while indirectly lowering BMD. From this we concluded that simply increasing body weight does not lead to an increase in BMD.

Several possible mechanisms have been put forward to explain the influence of body-fat mass on BMD. One possibility is aromatase, which converts male hormones into estrogen in adipose tissue. Synthesis and replenishment of estrogenic hormone is achieved in this way. Reid (29) suggested that, of the identified predictors of BMD, total body fat mass is quantitatively the most important for this reason. However, the subjects of their study were older and postmenopausal women. Douchi et al. (30) reported that lean mass rather than fat mass was a significant determinant of not only regional BMD but also total body BMD in pre-menopausal women. That is to say, in pre-menopausal females with regular menstruation, the effects on BMD of estrogen synthesized in adipose tissue are smaller because of female uterine hormone secretions.

In this study, the subjects were younger women ranging in age from 18 through 40 years with mostly regular menstrual cycles. It was therefore assumed that the influence of body fat on BMD would be different from that in postmenopausal women.

Although in this study a correlation was observed between BMD and BMI, the results suggested that body composition plays an important role in this correlation. The analyses conducted in this study were based on the hypothesis that the experience of childbirth and such lifestyle-based differences as diet and exercise habits would be reflected in the physique. At the same time, it is clear that physique is not able to account for all such lifestyle-based habits. The authors see a need for further detailed study and discussion regarding the correlation of BMD and life-style based habits.

In conclusion, this study analyzed the correlations of BMD with $\mathrm{BMI}$ and $\mathrm{BF} \%$ using a structural equation model in Japanese females aged 18 through 40 years. The results showed a positive correlation between BMD and BMI and an inverse correlation between $\mathrm{BMD}$ and $\mathrm{BF} \%$. At the same time, an increase in $\mathrm{BF} \%$ was noted as $\mathrm{BMI}$ increased. In other words, it was demonstrated that among subjects who have a similar BMI, BMD depends on BF\%. Therefore, this study suggested that it is necessary to take body composition measurements into account when examining the relationship between BMI and $\mathrm{BMD}$, especially in young females.

\section{References}

( 1 ) Mori S. Risk factor of osteoporosis. Osteoporosis Jpn. 1999; 21: 22-23. (in Japanese)

( 2 ) Renfro J, Brown JB. Understanding and preventing osteoporosis. AAOHN J. 1998; 46: 181-191.

( 3 ) Yoshimura N, Hashimoto T, Morioka S, Sakata K, Kasamatsu $\mathrm{T}$, Cooper C. Determinants of bone loss in a rural Japanese community: The Taiji Study. Osteoporosis Int. 1998; 8: 604-
610.

(4) The Ministry of Health, Labor and Welfare, National Nutrition Survey. Tokyo, Japan: Daiichi; 1997. (in Japanese)

(5) The Ministry of Health, Labor and Welfare, National Nutrition Survey. Tokyo, Japan: Daiichi; 1998. (in Japanese)

(6) The Ministry of Health, Labor and Welfare, National Nutrition Survey. Tokyo, Japan: Daiichi; 1999. (in Japanese) 
(7) The Ministry of Health, Labor and Welfare, National Nutrition Survey. Tokyo, Japan: Daiichi; 2001. (in Japanese)

( 8 ) Fujise T, Nagasaki K. Characteristics of anthropometry and physical fitness of masked obesity in young men and women. Tairyoku Kagaku. 1999; 48: 631-640. (in Japanese)

(9) Yamagishi H, Kitano T, Kuchiki T, Okazaki H, Shibata S. Association between body composition and body mass index in young Japanese women. J Nutr Sci Vitaminol. 2002; 48: 201-216.

(10) Ohno M, Ikeda Y. Relation between prevalence and body fat percentage and BMI in middle-age Japanese. Himan Kenkyu. 1998; 4: 60-64. (in Japanese)

(11) Ribot C, Tremollieres F, Pouilles JM, Bonneu M, Germain F, Louvet JP. Obesity and postmenopausal bone loss: the influence of obesity on vertebral density and bone turnover in postmenopausal women. Bone. 1988; 8: 327-331.

(12) Nishizawa Y, Koyama H, Shoji T, Aratani H, Hagiwara S, Miki $\mathrm{T}$, et al. Obesity as a determinant of regional bone mineral density. J Nutr Sci Vitaminol. 1991; 37: S65-S70.

(13) Takata S, Ikata T, Yonezu H. Characteristics of bone mineral density and soft tissue composition of obese Japanese women: application of dual-energy X-ray absorptiometry. J Bone Miner Metab. 1999; 17: 206-210.

(14) Kitano N, Sugimori H, Nakamura K, Futatsuka M, Inomoto T, Kitano T. Association of lean mass, fat mass, body mass index, and skinfold thickness on bone mineral density of young Japanese females: an age-controlled cross-sectional study. Showa Univ J Med Sci. 1999; 11: 23-31.

(15) Hirota T, Nara M, Ohguri M, Manago E, Hirota K. Effect of diet and lifestyle on bone mass in Asian young women. Am J Clin Nutr. 1992; 55: 1168-1173.

(16) Kajita E, Iki M, Tobita Y, Mitamura S, Kusaka Y, Ogata A, et al. Bone mineral density of the lumbar spine and its relation to biological and lifestyle factors in middle-aged and aged Japanese women (Part 3) Relationships of physical fitness and lifestyle factors to bone mineral density in premenopausal and postmenopausal women. Nippon Eiseigaku Zasshi. 1995; 50: 893-900. (in Japanese)

(17) Sakamoto Y, Nishizawa M, Sato T, Ohno M, Ikeda Y. Measurement of body fat by bioelectrical impedance analysis. Nippon Ningendokku Gakkaishi. 1993; 8: 38-41. (in Japanese)

(18) Regional Office for the Western Pacific, World Health Organization, The International Obesity Task Force. 2000. The Asia-Pacific perspective: Redefining obesity and its treatment.

(19) Minaguchi H, Gorai I, Taga M, Nakayama M, Tagauchi Y. Measurement of bone mineral density of radius by DTX-200 (OSTEOMETER). Nippon Sanka Fujinka Gakkai Kanagawa
Chihobukai Kaishi. 1995; 32: 12-16. (in Japanese)

(20) Hernandez-prado B, Lazcano-Ponce E, Cruz-Valdez A, Diaz R, Tamayo J, Hernandez-Avila M. Validity of bone mineral density measurements in distal sites as an indicator of total bone mineral density in a group of pre-adolescent and adolescent women. Arch Med Res. 2002; 33: 33-39.

(21) The Ministry of Health, Labor and Welfare. WHITE PAPER Annual Report on Health and Welfare. Tokyo, Japan: Gyousei; 2000.

(22) Fujiwara S. Epidemiology on bone mineral density among Japanese women. Nippon Rinsho. 2002; 798: 139-146. (in Japanese)

(23) Nishida H, Sugiura H, Takemoto Y, Onogi M, Shimazawa T, Miura $\mathrm{T}$, et al. Influence of bone density measurement at entrance into women's college on their subsequent consciousness to dietary life and bone-On the relationship of bone density difference to later results-. Gakkou Hoken Kenkyu. 1997; 39: 316-324. (in Japanese)

(24) Kaneko M, Miyake T, Yokoyama E, Harano S, Toki T, Komine $\mathrm{Y}$, et al. Standard radial bone mineral density and physical factors in ordinary Japanese women. J Bone Miner Metab. 2000; 18: 31-35.

(25) Akimoto Y, Yoshizumi N, Murai S, Hosoyachi A, Ogasawara $\mathrm{T}$, Izutsu $\mathrm{T}$, et al. Usefulness of bone mass measurement in young females and its relationship to background factors. Nippon Sanka Fujinka Gakkai Zasshi. 2001; 53: 635-639. (in Japanese)

(26) Lee JS, Kawakubo K, Sato H, Kobayashi Y, Haruna Y. Relationship between total and regional bone mineral density and menopausal state, body composition and life style factors in overweight Japanese women. Int J Obes. 2001; 25: 880886.

(27) Sasaki A, Ikeda Y, Gotou M, Matsushima I, Saga S. Optimum body weight aged 20-30 years old females based on BMI. Himan Kenkyu. 1997; 3: 114-118. (in Japanese)

(28) Kim H, Tanaka K, Amagai H, Suzuki T. Age-related changes of body composition by dual-energy X-ray absorptiometry in Japanese men and women. Taiikugaku Kenkyu. 1999; 44: 500-509. (in Japanese)

(29) Reid IR, Ames R, Evans MC, Sharpe S, Gamble G, France JT, Lim TMT, Cundy TF. Determinants of total body and regional bone mineral density in normal postmenopausal women-A key role for fat mass. J Clin Endocrinol Metab. 1992; 75: 45-51.

(30) Douchi T, Yamamoto S, Oki T, Maruta K, Kuwahara R, Yamasaki H, Nagata Y. Difference in the effect of adiposity on bone density between pre- and postmenopausal women. Maturitas. 2000; 34: 261-266. 